\title{
Action and interaction of penicillin and gentamicin on enterococci
}

\author{
FRANCISCO SORIANO ${ }^{1}$ AND DAVID GREENWOOD \\ From the Department of Microbiology, University Hospital, Queen's Medical Centre, Nottingham NG7 2UH, \\ UK
}

SUMMARY The action and interaction of benzylpenicillin and gentamicin on Streptococcus faecalis was studied using mainly turbidimetric methods. The minimum antibacterial concentration (MAC) of each antibiotic lay considerably below the conventionally determined minimum inhibitory concentration, and levels of the two agents exceeding the MAC were necessary in order to obtain a synergic interaction.

Evidence was obtained that gentamicin interfered with bacterial lysis induced by penicillin, and this suggests that the aminoglycoside is responsible for the bactericidal activity of the combination, the role of the penicillin being solely to facilitate access of the aminoglycoside to its target site. Our findings do not, however, fully support the generally held view that the increased permeability of enterococci to aminoglycosides is due to penicillin-induced cell wall damage. 'Persisters'-cells surviving prolonged exposure to the optimum lethal concentration of penicillin-were not killed by subsequent exposure to gentamicin if the penicillin was removed but were killed if the penicillin remained present.

For many years the combination of benzylpenicillin and streptomycin has been the treatment of choice for enterococcal endocarditis because the marked bactericidal synergy that is readily shown against many enterococcal strains in vitro is matched by clinical success. However, strains of enterococci that are highly resistant to streptomycin are not killed by the combination (Standiford et al., 1970), and gentamicin, which acts synergically with penicillin against almost all enterococci (Watanakunakorn, 1971; Calderwood et al., 1977), should probably replace streptomycin as the aminoglycoside of choice (Watt, 1978).

Synergy between penicillins and aminoglycosides is thought to be due to penicillin-mediated wall damage, facilitating entry of the aminoglycoside into the cell (Moellering and Weinberg, 1971). A great deal of work has been done on the interaction of these compounds against enterococci (see Jawetz (1975) for review), but relatively little has been done to study systematically the synergic interaction at different concentrations, particularly those lying below the minimum inhibitory concentration (MIC) where

1Present address: Fundación Jiménez Díaz, Departamento de Microbiologia, Ciudad Universitaria, Av. Reyes Catolicos, 2, Madrid, Spain

Received for publication 25 April 1979 a variety of antibacterial effects are known to occur (Greenwood, 1975; Lorian, 1975), or those at which penicillin exerts its optimal lethal effect (Eagle and Musselman, 1948).

In this investigation of the action and interaction of benzylpenicillin and gentamicin we have paid special attention to effects observed at sub-MIC and optimum bactericidal levels and have examined the susceptibility of penicillin-induced 'persisters' to the action of gentamicin.

\section{Material and methods}

The strain of Streptococcus faecalis used, designated Hook, was originally isolated from a case of subacute bacterial endocarditis. The strain belonged to Lancefield's group D, was bile tolerant, hydrolysed aesculin and arginine, and fermented mannitol but not arabinose.

Growth medium was the TRIS-buffered 'complete' medium (pH 7.2) described previously (Mawer and Greenwood, 1978).

Benzylpenicillin sodium (Glaxo Laboratories Ltd) and gentamicin sulphate (Nicholas Laboratories Ltd) were standard pharmaceutical preparations. Appropriate concentrations were freshly prepared, as required, in sterile distilled water.

TURBIDIMETRIC STUDIES

Twenty-millilitre volumes of broth were inoculated 1174 
with bacteria from an overnight broth culture to achieve an inoculum of $c a 5 \times 10^{5}$ bacteria per $\mathrm{ml}$ and incubated in the multichannel continuous opacity monitoring device described by Mackintosh et al. (1973). Antibiotic was either included in the broth at the beginning of the experiment or, in dense inoculum experiments, added when bacterial growth had reached a standard level of $30 \%$ of maximum (viable count ca $5 \times 10^{7}$ bacteria per $\mathrm{ml}$ ). The action of penicillin was halted, when required, by the addition of $0.1 \mathrm{ml}$ penicillinase (broadspectrum mixture of $\beta$-lactamases I and II; Whatman Biochemicals Ltd).

\section{VIABLE COUNTS}

Surface viable counts were performed by standard methods. In certain experiments, small numbers of survivors were detected by filtering cultures exposed to antibiotic through membrane filters (average pore size $0.45 \mu$ ) and incubating the washed filters on the surface of blood agar plates.

\section{Results}

A continuous opacity record of Str. faecalis Hook, in the presence of various concentrations of benzylpenicillin, is shown in Figure 1. Concentrations below $1 \mu \mathrm{g}$ per $\mathrm{ml}$ had little effect on bacterial growth, and $1 \mu \mathrm{g}$ per $\mathrm{ml}$ was regarded as the minimum antibacterial concentration (MAC), defined in the turbidimetric system as that concentration producing a reproducible deviation from the normal growth curve. The MIC, the concentration suppressing growth for the whole of the 20-hour incubation period, was $4 \mu \mathrm{g}$ per $\mathrm{ml}$. Cultures growing during the overnight incubation period in the presence of 1 and $2 \mu \mathrm{g}$ benzylpenicillin per $\mathrm{ml}$ were shown, on retesting in the turbidimetric system, to have acquired a small increment of resistance to the antibiotic in that they were able to grow without a prolonged lag phase in that concentration to which they had been previously exposed.

The response of the Hook strain to gentamicin is shown in Figure 2. Again, concentrations below the

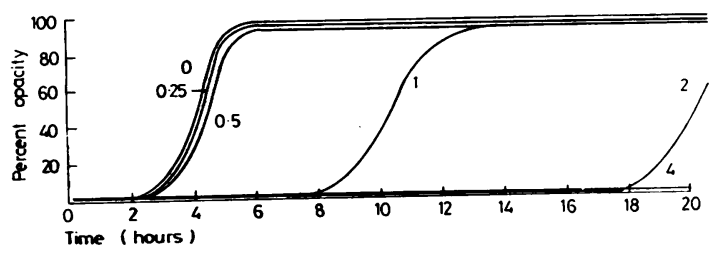

Fig. 1 Continuous opacity records of Str. faecalis (Hook strain). Penicillin added at time 0 to achieve concentrations ( $\mu$ g per $\mathrm{ml}$ ) shown.

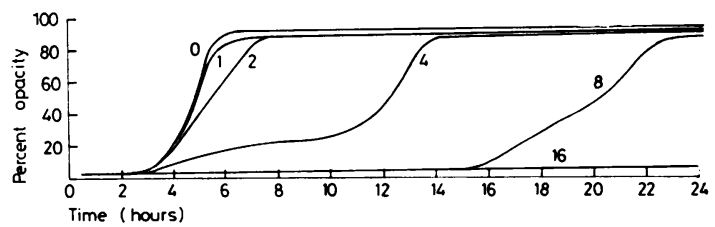

Fig. 2 Continuous opacity records of Str. faecalis (Hook strain). Gentamicin added at time 0 to achieve concentrations ( $\mu \mathrm{g} \mathrm{per} \mathrm{ml}$ ) shown.

MIC (16 $\mu \mathrm{g}$ per $\mathrm{ml})$ had a partial antibacterial effect, and cultures growing during overnight incubation after initial suppression of growth (ie, cultures exposed to 4 and $8 \mu$ g gentamicin per $\mathrm{ml}$ in Fig. 2) exhibited a small increase in resistance to gentamicin. The MAC of gentamicin was found to be $2 \mu \mathrm{g}$ per $\mathrm{ml}$.

Viable counts of cultures exposed to benzylpenicillin overnight (Fig. 3) showed that the optimal bactericidal concentration of benzylpenicillin was $4 \mu \mathrm{g}$ per $\mathrm{ml}$; concentrations above that level were less lethal, the so-called 'Eagle effect' (Eagle and Musselman, 1948). This effect was also seen in high inoculum experiments in the turbidimetric system in which high concentrations of penicillin $(>16 \mu \mathrm{g}$ per $\mathrm{ml}$ ) induced less lysis than lower levels (Fig. 4); in such experiments no inoculum effect was observed in that the MAC remained at $1 \mu \mathrm{g}$ per $\mathrm{ml}$ and the $\mathrm{MIC}$ at $4 \mu \mathrm{g}$ per $\mathrm{ml}$.

An inoculum effect was, however, observed with gentamicin. When tested against an inoculum of

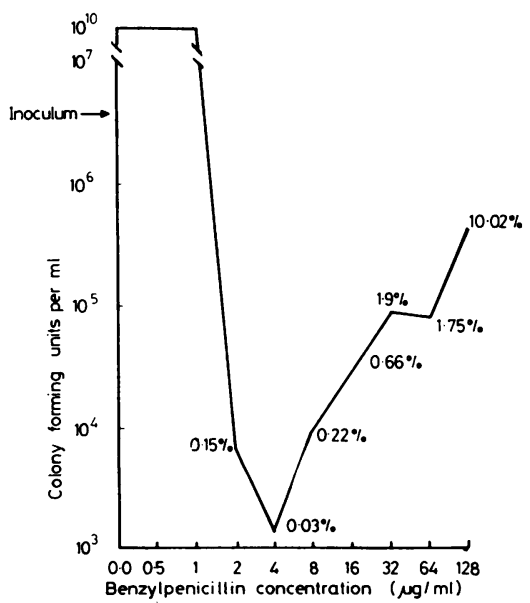

Fig. 3 Optimum dosage effect of penicillin against Str. faecalis (Hook strain). Number of colony-forming units (CFU) recovered after exposure of an inoculum of $5 \times 10^{\circ}$ CFU to various concentrations of penicillin overnight. 


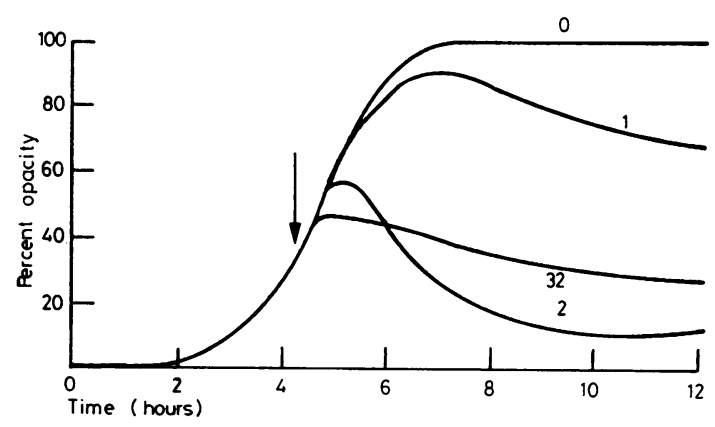

Fig. 4 Continuous opacity records of Str. faecalis (Hook strain). Penicillin added at arrow to achieve concentrations ( $\mu$ g per $\mathrm{ml}$ ) shown.

ca $5 \times 10^{7}$ bacteria per $\mathrm{ml}$, the MAC rose to $8 \mu \mathrm{g}$ per ml (Fig. 5).

\section{COMBINATION STUDIES}

Viable counts of cultures of the Hook strain of Str. faecalis exposed to penicillin and gentamicin, alone and in combination, demonstrated the classical bactericidal synergy between these compounds (Fig. 6). Concentrations at or above the MAC of the two components were necessary to achieve a combined bactericidal effect. Filtration experiments on cultures exposed to penicillin and gentamicin for 24 hours showed that complete sterilisation of the culture could be achieved with $\frac{1}{2}$ MIC gentamicin in the presence of concentrations of penicillin at or above the MIC (Table).

The interaction of sub-MIC concentrations of the two agents was also examined in the turbidimetric system. When Str. faecalis Hook was exposed to increasing concentrations of gentamicin (spanning the concentrations $1 \mathrm{MAC}$ to $\frac{1}{2} \mathrm{MIC}$ ) in the presence of $1 \mu \mathrm{g}$ benzylpenicillin per $\mathrm{ml}$, it was found that a concentration above the MAC of gentamicin was necessary to influence significantly the recovery of organisms during the overnight incubation period

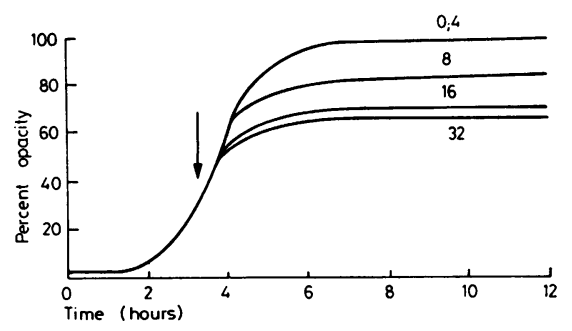

Fig. 5 Continuous opacity records of Str. faecalis (Hook strain). Gentamicin added at arrow to achieve concentrations ( $\mu \mathrm{g}$ per $\mathrm{ml}$ ) shown.

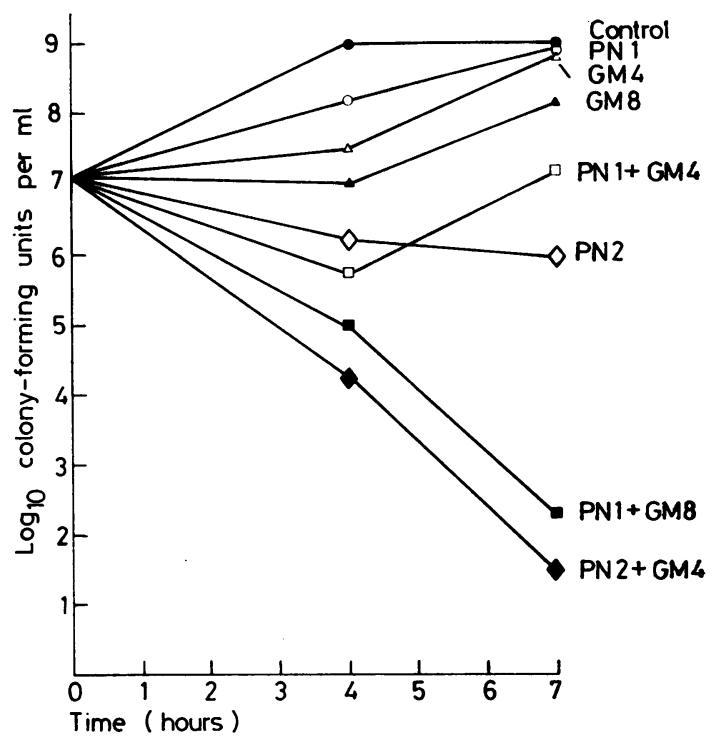

Fig. 6 Killing curves of Str. faecalis (Hook strain) exposed to various concentrations ( $\mu \mathrm{g} \mathrm{per} \mathrm{ml}$ ) of penicillin $(P N)$ and/or gentamicin $(G M)$.

Table Recovery of bacteria by membrane filtration after exposure to benzylpenicillin and/or gentamicin

Conc. of penicillin Number of colony-forming units recovered

( $\mu \mathrm{g}$ per $\mathrm{ml}$ ) in presence of:

\begin{tabular}{lll}
\cline { 3 - 3 } & No gentamicin & Gentamicin $8 \mu \mathrm{g} \mathrm{per} \mathrm{ml}$ \\
\hline 0 & $\mathrm{C}$ & $\mathrm{C}$ \\
1 & $\mathrm{C}$ & 25 \\
2 & $\mathrm{C}$ & 8 \\
4 & 590 & 0 \\
8 & $\mathrm{~N}$ & 0
\end{tabular}

$\mathrm{C}=$ confluent $\left(>10^{\circ}\right) ; \mathrm{N}=$ numerous $(>3000)$

(Fig. 7). In dense inoculum experiments, inhibitory concentrations of gentamicin appeared to interfere with the lytic activity of penicillin (Fig. 8).

FATE OF 'PERSISTERS'

The fate of penicillin-induced 'persisters' was examined by removing penicillin enzymically from cultures exposed to the antibiotic in the presence and absence of gentamicin. When cultures were exposed to levels of penicillin at, or just below, the MIC for 7 hours, regrowth of persisting bacteria was affected only by the simultaneous presence of concentrations of gentamicin exceeding the MAC. Overnight suppression of persisting bacteria was achieved with a level of $4 \mu \mathrm{g}$ gentamicin per $\mathrm{ml}$ (2MAC; 1/4MIC) (Fig. 9).

When gentamicin was withheld for 7 hours and added together with penicillinase, $4 \mu \mathrm{g}$ gentamicin 


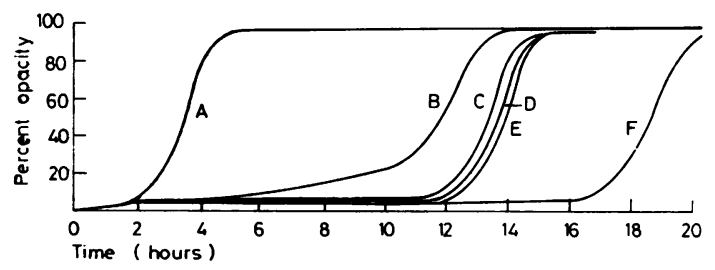

Fig. 7 Continuous opacity records of Str. faecalis (Hook strain). A: no antibiotic; B-F: antibiotic added at time $O$ to achieve concentrations ( $\mu \mathrm{g}$ per $\mathrm{ml}$ ) of B: gentamicin 8; $C$ : penicillin 1; D: penicillin 1 plus gentamicin 2; $E$ : penicillin 1 plus gentamicin 4; F: penicillin 1 plus gentamicin 8 .

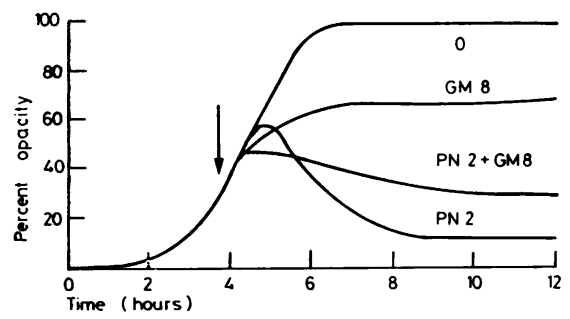

Fig. 8 Continuous opacity records of Str. faecalis (Hook strain). Penicillin (PN) andlor gentamicin (GM) added at arrow to achieve concentrations ( $\mu \mathrm{g}$ per $\mathrm{ml}$ ) shown.

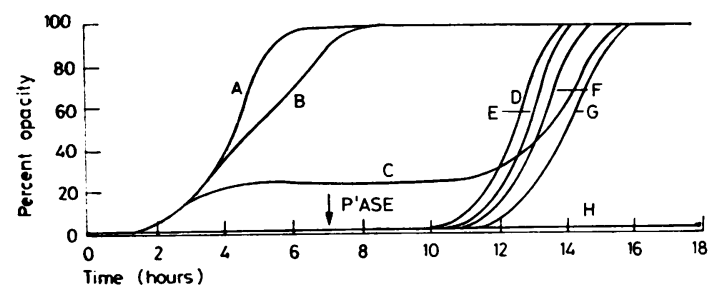

Fig. 9 Continuous opacity records of Str. faecalis (Hook strain). A: no antibiotic; $B$-H: antibiotic added at time 0 to achieve concentrations ( $\mu \mathrm{g}$ per $\mathrm{ml}$ ) of B: gentamicin 2; C: gentamicin 4; D: penicillin 2; E: penicillin 4; F: penicillin 2 or 4 plus gentamicin 1; G: penicillin 2 or 4 plus gentamicin 2; H: penicillin 2 or 4 plus gentamicin 4. Penicillinase added to cultures D to $H$ after 7 hours (arrow).

per $\mathrm{ml}$ was insufficient completely to suppress growth of persisters. An experiment was therefore designed to establish how long penicillin and gentamicin must be present together for complete suppression of persisters to occur. A series of cultures was exposed to $2 \mu \mathrm{g}$ penicillin per $\mathrm{ml}$, and sufficient gentamicin was added at hourly intervals to achieve a concentration of $4 \mu \mathrm{g}$ per $\mathrm{ml}$. The action of penicillin was halted after 7 hours in each case. The experiment is depicted diagrammatically in Figure 10. It was found that gentamicin had to be present together with the penicillin for at least 5 hours for persisters to be completely suppressed.

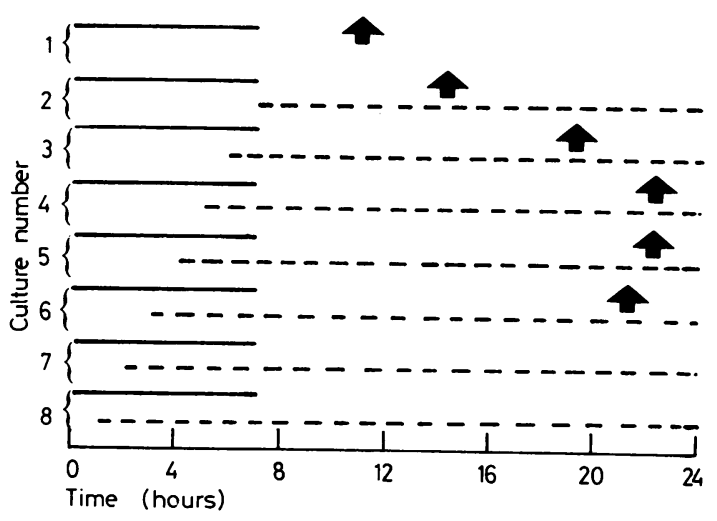

Fig. 10 Diagrammatic representation of experiment in which cultures of Str. faecalis (Hook) were exposed to penicillin (2 $\mu \mathrm{g} \mathrm{per} \mathrm{ml;} \mathrm{solid} \mathrm{line)} \mathrm{and} \mathrm{gentamicin} \mathrm{(4} \mathrm{\mu g}$ per ml; dotted line) for various periods of time. Penicillin activity was halted enzymically after 7 hours. Arrows indicate time at which regrowth occurred.

Further evidence that gentamicin was unable to kill persisters in the absence of penicillin was obtained by exposing cultures to the optimal bactericidal concentration of penicillin $(4 \mu \mathrm{g}$ per $\mathrm{ml})$ overnight. Penicillin action was halted with penicillinase, and sufficient gentamicin was immediately added to achieve concentrations of 4 or $8 \mu \mathrm{g}$ per $\mathrm{ml}$. Growth of persisters occurred after 13 hours' exposure to $4 \mu \mathrm{g}$ gentamicin per $\mathrm{ml}$ and after 16 hours' exposure to $8 \mu \mathrm{g}$ gentamicin per $\mathrm{ml}$.

Each of the main findings of this study was confirmed using another strain of Str. faecalis freshly isolated from a case of subacute bacterial endocarditis.

\section{Discussion}

Benzylpenicillin and gentamicin both exhibit considerable inhibitory activity at levels below those detected by the conventional MIC, and the endpoint of MIC titrations appears to be influenced in both cases by the ability of part of the population to break through inhibitory levels to re-establish a slightly more resistant culture during the incubation period. This raises the question whether bacteristatic synergy between these compounds, when detected by chessboard titrations, may be due to the mutual suppression of such adaptive variants. 
Bactericidal synergy between penicillin and gentamicin is manifested by a marked enhancement of the early lethal activity of the compounds. The present results reveal two interesting aspects of this interaction.

Firstly, levels of the two antibiotics exceeding the MAC were required for bactericidal synergy to occur. Thus, if it is true that the basis of synergy is that penicillin weakens the cell wall and the aminoglycoside is then admitted more readily (Moellering and Weinberg, 1971), the increase in accessibility must be fairly small (and perhaps embraces a larger fraction of the population), because the concentration of gentamicin required to obtain a synergic response was not less than that which alone could cause some inhibition of growth.

Secondly, gentamicin appears to antagonise the lytic activity of penicillin (Fig. 8). This suggests that once the gentamicin is admitted, it is responsible for most of the subsequent bactericidal effect.

One of the weaknesses of the permeabilisation theory of penicillin/aminoglycoside interaction is that it does not satisfactorily explain how persisters are killed by aminoglycosides. Persisters, first described by Bigger (1944), are those cells that survive exposure to lethal concentrations of penicillins while displaying no increase in intrinsic resistance to the drug. One theory of persistence depends on the fact that when penicillins cause lysis of Gram-positive bacteria, wall components, including lipoteichoic acid (LTA), may be released into the medium. LTA is an inhibitor of cell wall autolytic activity in Gram-positive cocci (Höltje and Tomasz, 1975), including Str. faecalis (Cleveland et al., 1976), so that, if the lethal activity of penicillins is a consequence of continued autolytic activity, as has been suggested (Rogers, 1967), persisters may be bacteria protected by LTA released by those cells that lyse first. It is possible that such bacteria incur sufficient structural damage to admit aminoglycosides even though they are not killed by the penicillin.

An alternative theory of persistence is that such cells are caught by the penicillin in a particular metabolic state-when they happen to have no cell wall growth points. Such cells need to employ autolytic enzymes-mucopeptide hydrolases-to provide gaps for the insertion of fresh cell wall material, so that if these enzymes are inhibited by penicillins, as has been shown for Escherichia coli (Hartmann et al., 1972), the cell is unable to grow until the penicillin is removed (Greenwood, 1972). If this hypothesis is correct, there is no reason why persisters should be hypersusceptible to aminoglycosides, because they do not have damaged walls. The present work confirms that persisters are not susceptible to gentamicin: even those cells conforming to a very strict definition of persistersthose surviving exposure to the optimal bactericidal level of penicillin for 24 hours-were not completely suppressed by subsequent exposure to gentamicin. Furthermore, as shown by Miles et al. (1951) using streptomycin and confirmed in the present study for gentamicin, the simultaneous presence of penicillin and aminoglycoside is required for synergy to occur. This suggests that increased permeability to aminoglycosides due to cell wall damage caused by the penicillin is not the whole explanation, because such damage takes time to repair and the aminoglycoside should be admitted for some time after the penicillin has been removed. In the present study, benzylpenicillin and gentamicin had to be present together for at least 5 hours for complete sterilisation of the culture to occur.

If gentamicin alone cannot kill persisters (even after prolonged exposure to penicillin) and yet can do so together with penicillin after several hours' simultaneous exposure, the conclusion seems inescapable that binding of penicillin to the cell facilitates entry of the aminoglycoside in some way, even in the absence of cell wall damage.

Dr Soriano was aided by a grant from the Juan March Foundation.

\section{References}

Bigger, J. W. (1944). Treatment of staphylococcal infections with penicillin by intermittent sterilisation. Lancet, 2, 497-500.

Calderwood, S. A., Wennersten, C., Moellering, R. C., Jr., Kunz, L. J., and Krogstad, D. J. (1977). Resistance to six aminoglycosidic aminocyclitol antibiotics among enterococci: prevalence, evolution, and relationship to synergism with penicillin. Antimicrobial Agents and Chemotherapy, 12, 401-405.

Cleveland, R. F., Wicken, A. J., Daneo-Moore, L., and Shockman, G. D. (1976). Inhibition of wall autolysis in Streptococcus faecalis by lipoteichoic acid and lipids. Journal of Bacteriology, 126, 192-197.

Eagle, H., and Musselman, A. D. (1948). The rate of bactericidal action of penicillin in vitro as a function of its concentration, and its paradoxically reduced activity at high concentrations against certain organisms. Journal of Experimental Medicine, 88, 99-131.

Greenwood, D. (1972). Mucopeptide hydrolases and bacterial 'persisters'. Lancet, 2, 465-466.

Greenwood, D. (1975). Differentiation of mechanisms responsible for inoculum effects in the response of Escherichia coli to a variety of antibiotics. Journal of Antimicrobial Chemotherapy, 2, 87-95.

Hartmann, R., Höltje, J-V., and Schwarz, U. (1972). Targets of penicillin action in Escherichia coli. Nature, 235, 426-429.

Höltje, J. V., and Tomasz, A. (1975). Lipoteichoic acid: 
a specific inhibitor of autolysin activity in pneumococcus. Proceedings of the National Academy of Sciences of the United States of America, 72, 1690-1694.

Jawetz, E. (1975). Actions of antimicrobial drugs in combination. Veterinary Clinics of North America, 5, 35-50.

Lorian, V. (1975). Some effects of subinhibitory concentrations of antibiotics on bacteria. Bulletin of the New York Academy of Medicine, 51, 1046-1055.

Mackintosh, I. P., O'Grady, F., Greenwood, D., Watson, B. W., Crichton, T. C., Piper, R., and Ferrer, A. (1973). A twelve channel bacterial growth monitoring system. Biomedical Engineering, 8, 514-515 and 526.

Mawer, S. L., and Greenwood, D. (1978). Specific and non-specific resistance to aminoglycosides in Escherichia coli. Journal of Clinical Pathology, 31, 12-15.

Miles, C. P., Coleman, V. R., Gunnison, J. B., and Jawetz, E. (1951). Antibiotic synergism requires simultaneous presence of both members of a synergistic drug pair. Proceedings of the Society for Experimental Biology and Medicine, 78, 738-741.
Moellering, R. C., Jr., and Weinberg, A. N. (1971). Studies on antibiotic synergism against enterococci. II. Effect of various antibiotics on the uptake of ${ }^{14} \mathrm{C}$-labeled streptomycin by enterococci. Journal of Clinical Investigation, 50, 2580-2584.

Rogers, H. J. (1967). Killing of staphylococci by penicillins. Nature, 213, 31-33.

Standiford, H. D., de Maine, J. B., and Kirby, W. M. M. (1970). Antibiotic synergism of enterococci: relation to inhibitory concentrations. Archives of Internal Medicine, 126, 255-259.

Watanakunakorn, C. (1971). Penicillin combined with gentamicin or streptomycin: synergism against enterococci. Journal of Infectious Diseases, 124, 581-586.

Watt, B. (1978). Streptococcal endocarditis: a penicillin alone or a penicillin with an aminoglycoside? Journal of Antimicrobial Chemotherapy, 4, 107-109.

Requests for reprints to: Dr D. Greenwood, Department of Microbiology, University Hospital, Queen's Medical Centre, Nottingham NG7 2UH, UK. 